\title{
Correction to: Volume Number of Journal of Biosystems Engineering
}

\section{Springer International Publishing}

Published online: 10 May 2019

(C) The Korean Society for Agricultural Machinery 2019

Due to a mistake the following articles.

https://doi.org/10.1007/s42853-019-00002-4 https://doi.org/10.1007/s42853-019-00008-y https://doi.org/10.1007/s42853-019-00005-1 https://doi.org/10.1007/s42853-019-00006-0 https://doi.org/10.1007/s42853-019-00004-2 https://doi.org/10.1007/s42853-019-00001-5 have been published with an incorrect volume number. The correct volume number is 44 .

The online version of the original article can be found at https://doi.org/ 10.1007/s42853-019-00002-4; https://doi.org/10.1007/s42853-01900008-y; https://doi.org/10.1007/s42853-019-00005-1; https://doi.org/ 10.1007/s42853-019-00006-0; https://doi.org/10.1007/s42853-01900004-2; https://doi.org/10.1007/s42853-019-00001-5

https://www.springer.com 